\section{LA VOZ DE LOS ARTESANOS EN EL RENACIMIENTO CIENTÍFICO: COSMÓGRAFOS Y CARTÓGRAFOS EN EL PRELUDIO DE LA “NUEVA FILOSOFÍA NATURAL"}

\author{
Antonio Sánchez* \\ Instituto de Filosofía \\ Centro de Ciencias Humanas y Sociales, CSIC \\ c/ Albasanz, 26-28 \\ 28037 Madrid
}

THE VOICE OF THE ARTISANS IN THE SCIENTIFIC RENAISSANCE: COSMOGRAPHERS AND CARTOGRAPHERS IN THE PRELUDE OF THE “NEW NATURAL PHILOSOPHY"

\begin{abstract}
The purpose of this article is to recover the voice of cosmographers, cartographers and navigators as artisans of science in the mid-sixteenth century. These artisans impulsed a new trend style in thinking nature, which later would be so relevant for natural philosophy. It has been argued that when speaking of modern science all natural sciences must be analyzed and not just the physical and mathematical disciplines. We should also consider the mechanistic conception of nature related to experimental philosophy, to which cartographers and cosmographers as Abraham Ortelius contributed. Starting off from Zilsel's writings, and through the recovery of the superior artisans of the XV and XVI centuries by authors such as Rossi, Crombie, Hooykaas, and most recently Pamela H. Smith, the discussion is now focused on formulating and solving the problems of nature and the position of the emerging disciplines devoted to the visual representation of space through new cartographical methods. It is to recognize these disciplines in a common "intellectual style" that also contributed to the origins of early modern experimental science.
\end{abstract}

KEY WORDS: Cosmography; Cartography; Early Modern Science; Artisanal Epistemology; Zilsel; Hooykaas; Ortelius; Natural Philosophy; theory; practice; Baconian Sciences.

\section{Hacia una epistemología artesanal: COSMOGRAFÍA Y CARTOGRAFÍA EN LA EUROPA DEL SIGLO XVI}

En 1531 Juan Luis Vives (1492-1540) escribía en su De tratendis disciplinis que los hombres doctos no debían dar la espalda al trabajo de los artesanos, sino más bien conocer los detalles de su actividad. La cita de Vives viene muy al caso. La mayoría de los historiadores de la ciencia moderna han mantenido un punto de vista demasiado clásico a este respecto, donde no se han tenido a penas en cuenta, ya no sólo las instituciones de las considera-
RESUMEN: En este artículo se pretende recuperar la voz de los cosmógrafos, de los navegantes y de los cartógrafos como artesanos de la ciencia que ya hacia mediados del siglo XVI iniciaron un nuevo estilo de pensar la naturaleza que más tarde interesaria a la nueva filosofia natural. Intento mantener que cuando se habla de la ciencia moderna deben analizarse todas las ciencias de la naturaleza y no sólo las disciplinas físico-matemáticas. Asimismo, deben considerarse las concepciones mecanicistas de la naturaleza emparentadas con la filosofia experimental, a la que tanto contribuyeron cartógrafos y cosmógrafos como Abraham Ortelius. Bajo la estela de los escritos de Zilsel y el rescate de los artesanos de los siglos XV y XVI por parte de autores como Rossi, Crombie, Hooykaas y, más recientemente Pamela H. Smith, se examina ese nuevo estilo de formular y resolver los problemas de la naturaleza por parte de las disciplinas emergentes que acabaron controlando la representación del espacio visual a través de nuevos métodos cartográficos. Se trata en definitiva de reconocer en estas disciplinas un estilo intelectual común que también contribuyó a los origenes de la ciencia experimental moderna.

PALABRAS CLAVE: Cosmografia; Cartografía; Ciencia Moderna; Epistemología Artesanal; Zilsel; Hooykaas; Ortelius; Filosofía Natural; teoria; práctica; Ciencias Baconianas.

das "ciencias menores", sino tampoco su propio quehacer científico. Si uno se detiene en el puritanismo de Charles Webster, el análisis contextual de Michael Hunter, la política radical y el latitudinarianismo de Margaret Jacob, el corporativismo profesional de Harold Cook, la historia de las universidades de Mordechai Feingold, los resultados epistemológicos de Barbara Saphiro o el discurso político de Shapin y Schaffer, un tema singular emerge en todos ellos: la práctica científica como una actividad que en el siglo XVII inglés dependía en gran parte de otro tipo de actividades (Lux, 1991). ¿Qué tipo de prácticas eran éstas? Aún así, han sido otros los autores que han defendido una 
postura menos ortodoxa ante la práctica científica de la Europa moderna'; autores que también han atendido a las actividades de "segundo orden" con anterioridad a la explosión de las grandes instituciones científicas como la Royal Society de Londres o l'Académie des sciences de París. Edgar Zilsel, Paolo Rossi, Peter Burke y, en buena medida, la tradición historiográfica francesa de la Escuela de Annales (Sánchez y Fragio, forthcoming) constituyen los cimientos de lo que se podría llamar la nueva "epistemología artesanal". Por epistemología artesanal entiendo, en consonancia con Pamela H. Smith², la forma en que los artesanos, como nuevas autoridades sociales e intelectuales, eran conscientes de su propia manipulación de la naturaleza a través de sus producciones materiales y sus procesos de creación. Este nuevo estatus epistemológico se produjo, en buena medida, por la aceleración del comercio mundial y la reactivación de la nobleza urbana. Se trata, en definitiva, de una nueva forma creativa de generar conocimiento mediante el control de la naturaleza.

En este artículo se intenta esclarecer, con el ejemplo de la cosmografía y la cartografía del siglo XVI, y siguiendo la tradición promovida por Olschki, Zilsel, Rossi y, más recientemente, Smith, en qué consistió esa epistemología artesanal que tan decisiva fue para el futuro del programa baconiano. Un programa que no contribuyó de forma categórica al desarrollo de las ciencias clásicas, pero si al resurgir de nuevos campos científicos que en la mayoria de los casos provenían de los oficios ya existentes (Kuhn, 1993). En un alarde de apropiación del conocimiento empírico Bacon reconstruyó los pilares sobre los que se había levantado el conocimiento artesanal que aún giraba a su alrededor. Una nueva "instauración" filosófica bajo la aureola de las artes mecánicas, la ciencia activa que promulgaba el bienestar de la humanidad. Las nuevas técnicas de observación y representación junto con sus procesos de cognición coincidieron con la reforma educativa de la filosofía. Y esto no fue una casualidad.

En la Europa del siglo XVI los artesanos de la ciencia e, incluso, los descubrimientos geográficos ${ }^{3}, 0$ ambos a la vez, propiciaron nuevas formas de representar el mundo más allá de las espiritualistas representaciones medievales y de las imprecisas cartas portulanas. Evidentemente, este argumento no simpatizaría con aquellos autores continuistas como Duhem, Crombie o Grant, pero podría tener una considerable carga persuasiva frente a autores como
Butterfield o Koyré, ya que la geografía, y por extensión, la cosmografía, la cartografía, la hidrografía y la navegación ejercieron una influencia primordial como disciplinas modernas que no fueron ajenas a la supuesta revolución de las ciencias. Dentro del campo de acción de estas ciencias matemático-geométricas, el mundo ya no estaba limitado al Mediterráneo. El mundo del Atlántico y, por extensión, del Nuevo Mundo abrió las puertas a un nuevo imaginario europeo donde el mundo físico crecía por instantes. La ciencia moderna también vino precedida por la nueva representación cartográfica del mundo. Los métodos de los cartógrafos portugueses ${ }^{4}$, italianos, españoles y flamencos contribuyeron a esa nueva forma de hacer ciencia (MartínMerás, 1993; Cerezo Martínez, 1994; Higueras Rodríguez, 2002). Sin ánimo de abrir un viejo debate, las raíces de la llamada Revolución Científica también podrían encontrarse en las actividades promocionales de un grupo de pensadores menores con una firme creencia en la "utilidad" del conocimiento, tanto teórico como práctico (Sandman, 2001). Si bien, el florecimiento de dicha revolución quedó más allá de la propuesta inicial.

El filósofo de la ciencia Edgar Zilsel mantuvo en la primera mitad del siglo XX ya no sólo que existía una vinculación ineludible entre la tecnología, las artes y el capitalismo moderno, sino que la separación en distintos estratos sociales tanto de artesanos como de filósofos naturales impidió que la emergencia de la ciencia moderna no se produjera antes de 1600 . Tras el derrumbe de dicha barrera social como consecuencia de la mirada de los académicos a las artes mecánicas, ambos sectores unieron sus fuerzas bajo la senda de las habilidades empíricas de los artesanos (Zilsel, 1942). La ruptura de las trabas sociales en la segunda mitad del siglo XVI debió ser tan intensa que provocó la reacción de escritores como Rabelais o Vives (Keller, 1950). A partir de entonces podría afirmarse que tanto los valores y objetivos políticos, o imperiales, como los valores económicos o comerciales, y en menor medida los de la ideología cristiana de los siglos XVI y XVII, coincidian institucionalmente en las cortes y academias, e individualmente en comerciantes, artesanos, oficiales y cosmógrafos.

Una vez que se empezó a difuminar la frontera que separaba las artes liberales de las artes mecánicas los progresos del conocimiento científico fueron proclamados bajo el programa científico y filosófico de Francis Bacon. Ya 
existía entre los navegantes, geodestas, topógrafos y artesanos una gran producción literaria en lengua vernácula que los príncipes, generales y comerciantes utilizaban como manuales de referencia. Fue en estos oficios donde la idea moderna de cooperación científica se desarrolló entre aquellos académicos que estaban próximos a los trabajadores manuales. El Theatrum de Ortelius, publicado en 1570, representó un ejemplo paradigmático de trabajo colectivo con una lista de colaboradores de casi ochenta cartógrafos. La navegación, la cartografía y, en general, todo aquello que el mundo moderno denominó "matemáticas aplicadas" pudieron ser las herramientas de las que Bacon se nutrió para desarrollar sus implicaciones filosóficas y culturales. En tiempos de la reina Elizabeth, un reinado que fue desde 1558 hasta su muerte en 1603, la Corona inglesa envió una comisión de expertos a la Casa de la Contratación de Sevilla, fundada en 1503 por los Reyes Católicos, para comprobar el funcionamiento científico y burocrático de una institución que encarnaría a la Casa de Salomón de la Nueva Atlántida. Contra el escolasticismo primero y frente al humanismo después el programa baconiano supuso el punto de inflexión a partir del cual se forjó el ideal de progreso de la civilización ${ }^{5}$. El cosmógrafo Pedro Apiano o el cartógrafo Gerard Mercator fueron algunos de esos artesanos superiores, como Durero o Gemma Frisius, que anticiparon las ideas de Bacon con la reivindicación del uso de la perspectiva, de la proyección y de los métodos geométricos para el dominio y control de la naturaleza.

Zilsel sugiere que busquemos en otras fuentes las raices tanto de la filosofía natural del Renacimiento tardío como del método experimental. Lejos de hallar la respuesta en las tesis aristotélicas o en la supremacía de la palabra, convendría girar la mirada hacia el entusiasmo de la experiencia física, el experimento y la observación; buscar entre aquellos creadores que elaboraban el conocimiento técnico y científico con su mente y con sus manos (Zilsel, 1940). Entre ellos se encontraban cirujanos, navegantes, cosmógrafos, constructores de instrumentos, una suerte de ingenieros que dadas las dificultades técnicas de sus ocupaciones iban alternando su oficio hacia la experimentación y el empirismo ¿Hubiera existido la ciencia experimental tal cual la conocemos de no haber sido demolida la barrera entre las artes liberales y las artes mecánicas? ¿Se preocuparon los respetables académicos de las artes mecánicas por su potencial económico? Resultaría una ardua tarea determinar qué sector de la ciencia -si artesanal o académica- tuvo una mayor influencia sobre el otro, pero en cambio cabría afirmar que si unos aportaron los experimentos y las observaciones, los otros suministraron la teoría y las matemáticas para el desarrollo de la ciencia natural (Zilsel, 1941).

Alistair C. Crombie, y en menor medida J. H. Randall Jr., ha señalado que la acción de estos grupos de trabajadores se desenvolvió, aunque sin dejar de mantener un contacto con ellas, fuera de las universidades, donde sin regirse por una formación rigurosa desarrollaron una serie de habilidades que facilitarian el dominio de la naturaleza (Crombie, 1980; Randall, 1961). Un dominio que comenzaba con la construcción material e instrumental y que acababa con análisis cuantitativos, poniendo así en evidencia la mensurabilidad de la naturaleza. Más allá del uso de la palabra y de la certeza de la escritura, estos nuevos procedimientos permitieron el control de las formas de representación del espacio, ya fuera mediante la perspectiva en pintura, por medio de la proyección en cartografía o por la construcción de relojes mecánicos en horolojía ${ }^{6}$. En este sentido los nuevos usos estéticos y tecnológicos de la trigonometría topográfica, de las coordenadas cartográficas o de las grabaciones numéricas no deben confundirse con los objetivos de la filosofia, pero en cambio sí debe reconocerse un estilo intelectual que desembocaría en lo que Crombie ha señalado como el "tercer escenario" de la ciencia moderna. Una nueva filosofía experimental centrada en el saber físico-matemático. Práctica y teoría, investigación científica y composición artística, análisis racional y análisis material contribuyeron a la historia intelectual del movimiento científico europeo bajo la premisa de la representación y de la manipulada imitación de la naturaleza. Tanto en la ciencia artesanal como en la ciencia académica el hombre se ha relacionado con la naturaleza como receptor, como conocedor y como sujeto de conocimiento sin necesidad de establecer un clasismo epistemológico que supere cualquier barrera temporal.

¿Cómo la metodología, la epistemología y, en el fondo, la historia del ethos tecno-científico de los que producian con sus manos, se convirtió en la piedra de toque de la nueva filosofía natural gobernada por aquéllos que trabajaban con su mente, artífices de grandes sistemas de pensamiento? ¿Dónde quedaba ahora la manipulación lingüistica y dónde la manipulación de objetos materiales? ¿Dónde se sitúa en esta narrativa sobre el nacimiento de la modernidad el antiguo esquema aristotélico que separaba la teoría, los silogismos lógicos y las demostraciones geométricas, de

(n)


la práctica, del conocimiento humano y sus experiencias particulares? ¿Hasta qué punto las figuras marginales y sus prácticas ayudan a iluminar los procesos de cambio histórico? El trabajo de teorización empírica desarrollado por los artesanos del siglo XVI podría resumirse en la elección de la naturaleza como fuente del conocimiento, en el acuerdo unilateral de asediar corporalmente la materia activa de la naturaleza, en experimentar esa lucha sólo mediante la reproducción e imitación, de tal modo que se constituya un tipo de conocimiento (Smith, 2004); no necesariamente como espejo de la naturaleza, sino también como habilidad para reproducir el poder creativo de la naturaleza. Fue este proceso de validación del conocimiento, o epistemología artesanal, la que algunos reformadores como Paracelso o Bacon incorporaron a su filosofía, aunque en ocasiones prescindiendo de la corporeidad sin necesidad ya de observar, recordar y captar corporalmente la naturaleza (Smith, 2000). Pero no siempre se prescindió del cuerpo. El interés de los académicos o nuevos filósofos, de finales del siglo XVI y principios del XVII, por la obtención de conocimiento natural permitió que la epistemología artesanal fuera incorporada a un nuevo discurso filosófico sobre la naturaleza, hasta el punto de que a finales del siglo XVII empezó a formar parte del currículo universitario. Si la adquisición de experiencia perturbó la vida diaria del naturalismo renacentista también provocó las aclamaciones barrocas de la nueva filosofía natural (Findlen, 1993; Smith, 1999; Gerbi, 1978).

\section{Un nuevo artesano del cosmos: Abraham Ortelius (1527-1598) y el teatro del MUNDO}

En el siglo XVI las políticas europeas dominadas por los Habsburgo centraron su atención no sólo en lo que podriamos llamar las "ciencias duras", sino también en el patrocinio de las matemáticas prácticas y artes mecánicas. Las políticas científicas de los príncipes consideraban los mapas topográficos, las cartas de navegación, los compases de proporción y los instrumentos para el desarrollo del método de la triangulación, fundamentales para el gobierno de sus territorios, el control de sus recursos, la propaganda de su poder y la expansión y protección de su autoridad. La realización de mapas e instrumentos cartográficos, como el teodolito, ejercieron una influencia decisiva a la hora de delimitar los deberes jurisdiccionales y los derechos económicos de la corte (Moran, 1991; Pimentel, 2001). El trabajo práctico de levantar un mapa, de explorar el territorio, de relacionarse corporalmente con la naturaleza que tanto interesó a la nueva filosofía natural se convertía también, tras su producción, en ocio y ostentación política, en un nuevo carácter estético que unía la ciencia con el arte, ahora desde la representación de la grandeza de los imperios, a la que los príncipes más ambiciosos no eran ajenos.

En este sentido la cosmografía se complementó con las pretensiones imperiales de la Europa moderna. Como un espejo de imperios, más que de príncipes, la cosmografía trataba de unificar el cielo y la tierra de tal manera que el mundo entero y sus partes fuesen visibles y mensurables. Para lo particular integraba dentro de sí la navegación, la cartografía o la topografía, disciplinas, todas ellas, que compartían un cierto aire de familia, una forma geométrica y matemática de operar. A fin de cuentas la cosmografía era una ciencia matemática, una ciencia de lo universal y de lo particular, de lo natural y de los hechos mundanos; pertenecía a la esfera de la acción y de la contemplación. Si en principio no coincidia con los supuestos de la filosofía natural contemporánea al menos sí compartieron su ethos material (Bennett, 2003).

¿Cuál era la relación que podrían mantener los problemas prácticos de la cosmografía, la cartografía y la navegación con el mundo natural? ¿Acaso la producción instrumental de estas ciencias reveló algún tipo de verdad sobre el mundo natural? Este tipo de disciplinas prácticas propiciaron, mediante el uso de instrumentos y la representación de imágenes, el dominio del mundo natural, el paso de la filosofía mecánica a la filosofía natural. Estos artesanos que trabajaban ya no sólo dentro de grupos técnicos determinados -arquitectura, perspectiva, fortificación, navegación, agrimensura, artillería-, sino también dentro de colectivos geográficos -como Florencia, Nuremberg, Lovaina, Amberes o Sevilla- estaban rodeados por los mismos factores que los filósofos naturales: manipulación de libros e instrumentos, recursos de impresión, talleres, universidades, centros de comercio activo, navegación. La separación que podría existir entre aquellas disciplinas que estaban bajo el amparo de las matemáticas aplicadas, es decir, aquellos artesanos cuyas habilidades ilustraban el entendimiento de la naturaleza, y aquellas categorías de la 
filosofía natural, o lo que es lo mismo, la preocupación por el entendimiento causal y teorético del mundo natural, era menor de lo que se ha imaginado (Bennett, 1986).

A lo largo de todo el siglo XVI existió un importante grupo de practicantes fuera de los ámbitos universitarios cuya filosofía activa descansaba en el conocimiento matemático como paradigma del conocimiento humano, tanto por su fiabilidad, eficacia y autoridad como por su utilidad y aplicabilidad. Este conjunto de navegantes, cartógrafos, geómetras o aritméticos ejercian un importante grupo de presión no sólo porque en ocasiones gozara de los favores de la corte, sino porque también se apoyaba en una nada desdeñable producción bibliográfica en lengua vernácula. Ésta ha sido una ruta desatendida por la historia de la ciencia, pero gracias a pequeñas adaptaciones ha sido reconducida dentro del dominio de la filosofía natural. El mecanicismo, la experimentación y la instrumentación requerida para su desarrollo fueron lugares comunes (Bennett, 1986).

Tras infinidad de inconvenientes instrumentales y de problemas científicos difíciles de resolver, la representación cartográfica alcanzó la nitidez esperada que los acontecimientos de principios de siglo parecían presagiar. La aparición en los Paises Bajos primero de Mercator y después de Ortelius en la segunda mitad del siglo XVI, como los dos grandes promotores de la nueva ciencia cartográfica, marcó el rumbo, también en España, de los aspectos formales y científicos a la hora de levantar un mapa. Dos acontecimientos fueron los responsables: la proyección Mercator de 1569 y el Theatrum Orbis Terrarum de Ortelius publicado en 1570. A partir de entonces, las pautas a seguir para la representación en plano de la esfera terrestre y la imagen del mundo contenida en un solo volumen facilitaron las vías de acceso hacia un mundo cercado y dominado por la vista. La aparición de estos dos hitos de la historia de la cartografía acabó casi definitivamente con la sombra de Ptolomeo.

Ortelius fue un hombre apreciado en toda Europa y, especialmente, en los contornos imperialistas de raigambre erasmista. Ortelius gozó del respeto de las cortes de Viena y Madrid. En 1573 fue nombrado por la Corona de Castilla "geógrafo real", por influencia de su amigo Benito Arias Montano, quien había llegado a Amberes para dirigir la impresión de la Biblia políglota en los talleres de Cristóbal
Plantino. Además de coleccionista y comerciante, Ortelius también fue cartógrafo.

La cartografía de Ortelius, junto con las obras de geometría, óptica y arquitectura, ayudaron a reflexionar sobre el espacio en el Renacimiento europeo. Sus trabajos cartográficos comenzaron a conocerse en los años sesenta ${ }^{7}$, donde coincidió en Amberes con otros célebres cartógrafos como Hieronimus Cock, Gérard o el propio Mercator, entre otros. La labor de Ortelius no se reduce al Theatrum, sin embargo en nuestro estudio nos limitaremos exclusivamente a este trabajo.

En algunos de sus mapas, como también ocurre en el Theatrum, se deja entrever la asociación renacentista entre la acumulación y la colección de bienes con el cuidado por el gusto y el virtuosismo (Cook, 2007). Estos mapas y el Theatrum, como la Historia Naturalis de Plinio o la Geographia de Ptolomeo, eran pequeños gabinetes de coleccionista, no de cosas naturales, sino de representaciones cartográficas del mundo, de acuerdo a la información de muchas personas, adquirida gracias al reconocimiento del terreno y a los viajes transoceánicos. No en vano, Ortelius publicó algunos mapas del sur de Francia y de la Península lbérica con la información que su amigo Carolus Clusius trajo de sus viajes.

Sin duda, el gran tesoro cartográfico de Ortelius fue el Theatrum Orbis Terrarum publicado en 1570. Con anterioridad al atlas de Ortelius existieron otros libros con mapas, pero ninguno de ellos ha sido considerado el primer atlas del mundo, privilegio que si ostenta el Theatrum (Van den Broecke, Van der Krogt y Meurer, 1998). La obra magna del cartógrafo de Amberes se caracterizaba, principalmente, por la subordinación del texto a la imagen, por la homogeneización de la exposición cartográfica y por el paulatino acuerdo de presentar las ediciones impresas. En este sentido fue el primer ejemplar que vio la luz como un mapa de mapas. Esta obra hizo de Ortelius algo más que un mero editor, un meta-cartógrafo, un nuevo artesano del mundo, e hizo suya una nueva forma de narración cartográfica.

Los atlas de finales del siglo XVI surgieron de la necesidad de recopilar en un solo ejemplar encuadernado una serie de mapas ordenados de acuerdo a una secuencia lógica. Era preciso recopilar a través de imágenes la totalidad del mundo descubierto. Lejos de presentarse ante el observador 
como un mero libro de mapas de carácter enciclopédico regido por los valores de la acumulación y el almacenamiento, los atlas no sólo cumplian con la función social de educar geográficamente a los ciudadanos del Renacimiento, sino que también informaba, a la manera de periódico cartográfico, a las cortes más influyentes de Europa. Desde los atlas que llegaban a Castilla, Felipe II se encontraba en disposición de ver todo el mundo descubierto ante sus ojos. Desde El Escorial, el rey se sentía dueño y señor del mundo que sus artesanos habian recreado para él.

Con los atlas el libro ejerció más que nunca su fuerza de sintesis para ofrecer a los ciudadanos renacentistas una imagen del mundo a la vez parcial y global. El formato libro sirvió para que un público cada vez más amplio leyera la historia contemporánea. Una historia que entraba por los ojos y no por los oídos. El Theatrum de Ortelius representa el caso más notorio dentro de esa historia renacentista de la cultura visual, una historia marcada por las necesidades geográficas de reflexionar sobre los espacios de representación de los conocimientos (Besse, 2007). El Atlas de Ortelius no era entonces un mero objeto material. Como su título indica, quien abre el Theatrum está dispuesto al espectáculo, a un modo de figuración, a un bosquejo de conocimiento que va más allá de la mirada, pero al que no se llega sino por la contemplación. El Atlas, y los mapas que contenían, en tanto que instrumentos de pensamiento, hicieron posible un nuevo imaginario espacial más allá de la imagen artística y científica al desnudo, un teatro de auto-representación.

El teatro barroco redujo, como nunca antes se habia hecho, el macrocosmos al microcosmos mediante un espectáculo representacional que ponía en evidencia los productos de la ingenuidad e invención humana. El mayor logro de la idea de teatro fue la recreación del mundo en microcosmos, el mundo del creador en escena. Un meta-teatro del mundo que intentaba representar la realidad con fines didácticos y metafóricos. Como ilustraba el drama de Calderón de la Barca, una realidad que conjugaba tanto el emplazamiento del drama cósmico de la redención como el cotidiano engaño de la vida diaria. La idea de teatro figuró como el vehículo idóneo de un dualismo insalvable entre lo material y lo espiritual, lo real y lo aparente, la verdad y la mentira, las palabras y las cosas, la teoría y la práctica, la realidad y su representación (Smith, 1994b; Rodríguez de la Flor, 1999, 2005). Los teatros de finales del siglo XVI y principios del siglo XVII, como el orteliano, constituian auténticos trozos de realidad.

Ortelius creó su propio museo científico, su propio gabinete de curiosidades para poder estudiar y visualizar el mundo sin necesidad de salir de su estudio. El Theatrum representaba, como los museos, un espectáculo para la vista. Fue un gran éxito editorial desde la fecha de su aparición hasta bien entrado el siglo XVII, pese a su elevado precio (Van den Broecke, Van der Krogt y Meurer, 1998).

A partir del Atlas de Ortelius este género descriptivo se convirtió en una nueva forma de conocimiento objetivo como consecuencia de una nueva forma de relacionarse con la naturaleza. Este conocimiento estaba legitimado por la idea de información, recopilación y acumulación, categorias que le eran inherentes. Se trataba de una imagen del mundo a la vez particular y universal. A través del atlas podía leerse la historia contemporánea, una historia transmitida de observador en observador. Se trataba de una "de-mostración" del mundo que cada uno debía "interpretar" según su criterio. El Theatrum significaba un espectáculo para la mirada, un escenario montado para deleite del espectador, como si se tratara de una imagen fiel de la realidad, en definitiva, un espejo a escala de la naturaleza. El Atlas de Ortelius, como otros teatros del siglo XVI -anatómicos, botánicos, zoológicos-, representaba el teatro del mundo mediante diversas formas de representación cartográfica. En el folio tres de la edición española de 1588 apunta Ortelius:

Y cuanto ya estamos hechos algún tanto al uso de ellas, y por ellas hemos alcanzado alguna noticia siquiera mediana de la Geografía, cualquier cosa que leyéremos, teniendo delante de los ojos estas cartas (mapas) como unos espejos de las cosas, queda más impreso en la memoria (Ortelius, 1570).

La posesión no sólo de la naturaleza mediante gabinetes de curiosidades o jardines botánicos, sino también la posesión de bonitos libros que resumían el conjunto de la naturaleza en tamaño reducido supuso, durante el Renacimiento, un elemento importante para el esplendor de prestigiosas familias, que dando a conocer sus nuevas adquisiciones, gozarian de los elogios de sus amistades $y$, a la postre, generarian más riqueza de la que ya ostentaban. La posesión de estos resúmenes completos de la naturaleza otorgaba igualmente fama y autoridad a quienes los poseian y, en 
el caso del Theatrum y de España, se convirtió en una cuestión de Estado, era necesario para la prosperidad del mismo. En este caso, los bienes materiales desembocaban en influyentes valores morales (Cook, 2007).

Sorprende el eclecticismo de Ortelius para ensamblar las piezas cartográficas disponibles. Sólo cartógrafos como Mercator y Ortelius supieron articular con fortuna las piezas de las que dispusieron. Para verificar y demostrar cómo era el mundo, y representarlo, se necesitaba un instrumento, y para juzgar la precisión del instrumento se necesitaba una demostración (Cook, 2007). La proyección de 1569 y el atlas de 1570 fueron sus aportaciones.

Los mapas y los atlas contribuyeron al gran mundo material y visual que conocieron las personas del Renacimiento. El mapa de Mercator y el Atlas de Ortelius no significaron meramente conceptos aceptados sin más, sino descripciones del mundo y los acontecimientos asociados a ellas. No pertenecían al mundo de la especulación, sino de los hechos. Ellos mismos generaban certidumbre. Bajo estas premisas se representaba cartográficamente el mundo en el siglo XVI y así se aproximaron los seres humanos al conocimiento. La adquisición y transmisión de información adecuada jugó un papel decisivo, pero aún fue más importante el acuerdo entre personas de la misma opinión, regidos por ciertos deseos e intereses más que por factores intelectuales. La transformación de la representación cartográfica y, en consecuencia, del conocimiento, se debió más a la producción, acumulación e intercambio de información -de la que por otra parte dependía el comercio- del previo contacto con la naturaleza (Cook, 2007) que de cualquier otro factor innato a la mente humana. El alto grado de aceptación de estos valores brindó una descripción del mundo cada vez más adecuada. Una representación del mundo que se consideraba cada vez más precisa, conforme a los secretos de la naturaleza, fue a la par de una mayor experiencia personal de aquellos que estaban cualificados para ello, mediante una vía empírica de conocimiento. Ésta fue la forma en que se conocía, se experimentaba y se poseía la naturaleza.

Los valores de la ciencia parecian ser aquellos que gobernaban el mundo del comercio y el mercantilismo: el viaje, el intercambio, la conmensurabilidad -las dificultades que se derivan de encontrar un patrón de medida, un común denominador-, la credibilidad, las mejoras materiales y la preferencia por un lenguaje claro y preciso. Tanto en un campo como en otro existía un cierto compromiso por el conocimiento objetivo y una mirada atenta de las colectividades hacia la forma en que ese conocimiento se presentaba. Cuando este tipo de valores se convirtieron en el objeto de la filosofía natural un cambio se produjo en la forma de hacer ciencia. Las categorias inherentes al mundo del comercio sentaron las bases del establecimiento de la nueva ciencia para los contemporáneos (Cook, 2007). El movimiento de personas y de objetos, el cambio y conocimiento del mundo tras su descubrimiento, la acumulación de datos, su catalogación y la representación de la esfera desembocaron en esta serie de valores que afectaron tanto a comerciantes como a navegantes y cosmógrafos.

\section{Conclusión: CRUZANdo las COLUmNas de HÉrCules}

Los viajes de los descubrimientos no sólo provocaron transformaciones en disciplinas como la cosmografía o la navegación, sino también en todas aquellas ciencias emparentadas con la historia natural. El proceso entre los primeros viajes transoceánicos y los trabajos científicos de principios del siglo XVII representan un período de incubación de la nueva filosofía natural. La tendencia empirista que intentaba resolver los problemas científicos a través de la contrastación de los resultados obtenidos mediante la experiencia se impuso a las discusiones escolásticas. Autores como Bernard Palissy o Martin Waldseemüller ya se habían adelantado, a lo largo y ancho del siglo XVI, a los trabajos de Gilbert o Kepler (Hooykaas, 1987; Capel, 1985).

Con el trabajo de Ortelius no pretendemos establecer una conexión directa de lo que fue la cosmografía y la cartografía en la Europa del siglo XVI con las pretensiones especulativas de la nueva filosofía natural promulgada por Francis Bacon. Los mapas del Theatrum representaban la naturaleza de forma tangible y visible. En el marco del imperio español, las representaciones ortelianas también quedaban lejos de la antigua filosofía natural de corte aristotélica. En una política dominada por un sistema de mecenazgo al que en gran parte sólo le preocupaban los resultados utilitarios, la metafísica aristotélica no tenía nada que hacer (Portuondo, 2005). La cosmografía de Or- 
telius no sólo tenía el propósito de abarcar y rodear el mundo, sino también de explicarlo. Y para esta labor la filosofía natural aristotélica ya no era adecuada. La misión de los cosmógrafos hacia finales del siglo XVI había superado la mera tarea de la descripción.

No se pretende plantear como una novedad el hecho de que se haya aceptado la capacidad explicativa de las disciplinas geométrico-matemáticas, su consecuente adaptación a una metodología experimental y su acomodación a una narrativa mecanicista de la causalidad. Pero sí, como ha sugerido Jim Bennett, el hecho de que -con anterioridad al advenimiento de la filosofía natural como se conoce hoy día- la geometría y sus manifestaciones cartográficas demostraran su poder explicativo sobre el mundo natural (Bennett, 1998). Su retórica, coherencia y persuasión técnica acabaron por disciplinar la nueva filosofía natural. Por encima de las derivas epistemológicas se encontraban las agendas de las políticas europeas, las exploraciones de nuevos territorios y el cercamiento visual del globo. Los nuevos artesanos del mundo ofrecieron sus herramientas y las pusieron a disposición de los nuevos intelectuales. Se desplazaron de la acción a la organización del conocimiento. El puente entre ambos espacios lo levantaron, entre otros, los mapas, las cartas náuticas, los globos y los atlas.

En los siglos XV y XVI se produjeron no pocas transformaciones en el ámbito de la ciencia popular y aplicada. La forma en que los habitantes europeos pensaron y se relacionaron físicamente con el medio ambiente sufrió algunas transformaciones. La solución pasaba por la aportación de remedios prácticos apoyados, en la mayoría de los casos, en intercambios culturales -ideológicos y materiales- y la sofisticación e invención de nuevas tecnologías como la imprenta. Estos factores junto con los conocimientos teóricos, las técnicas instrumentales y las formas de representación del mundo contribuyeron a explicar los modos de conocer que utilizó la cartografía. Los nuevos conocimientos matemáticos y geométricos que facilitaron la proliferación de tratados sobre cosmografía, cartografía y navegación, como consecuencia de la difusión que a partir de entonces proporcionó la imprenta, propiciaron la mejora del diseño naval, de los métodos topográficos y de la cartografía en general. En definitiva, con los avances de estas ciencias aumentaron de forma vertiginosa las transacciones comerciales por todo el globo (Brotton, 2003).
Podríamos concluir que los problemas derivados de la ciencia aplicada por la necesidad de agrandar las fronteras imperiales en la búsqueda de nuevos territorios transoceánicos, transformaron sustancialmente la forma que hasta entonces habia existido de representar el mundo. Este cambio de actitud que hizo dar prioridad a la experiencia por encima de cualquier otro valor como resultado de los largos viajes hacia el Nuevo Mundo no sólo afectó a la representación cartográfica, sino también a otras muchas disciplinas científicas como la medicina o la historia natural, que a partir de entonces modificaron sus métodos de trabajo (Hooykaas, 1987).

A la manera en que Peter Burke en su ya célebre Popular Culture in Early Modern Europe, publicado en 1978, intentó dar voz a una cultura que ya por sí misma era una cultura oral, en este artículo se ha intentado agudizar la voz de otro tipo de cultura moderna, la cultura artesanal como una cultura vinculada a la nueva filosofía natural del siglo XVII ¿Podría confirmarse, de una vez por todas, el éxito de la clase hegemónica en la revolución de las ciencias sin la colaboración de los artesanos? No, sin duda. El propósito aquí ha sido, como podria hacerse entre la actividad artística y científica del mismo período, el de unir, más que separar, entre clases sociales de científicos.

En el ámbito de las ciencias, más allá de la revolución en astronomía y en física asociada a los nombres de Copérnico, Kepler, Galileo y Newton, otros fueron los ámbitos que contribuyeron a un nuevo movimiento preocupado por la matematización y geometrización del mundo. La mensurabilidad de la naturaleza, la observación, el empirismo, la experimentación y la clasificación no sólo fue un programa propugnado por las ciencias baconianas de principios del siglo XVII, sino que también se extendió a nuevas áreas que incluian tanto las bellas artes como las artes plásticas durante todo el siglo XVI. Sus ambiciones en la resolución de problemas prácticos tuvieron un efecto transformador sobre la forma de entender el mundo natural y el mundo de las artes a partir, sobre todo, de la era de los descubrimientos.

La aportación de los artesanos ya no sólo transformó la ciencia a nivel técnico y conceptual, sino la cultura europea en el sentido en que proporcionó nuevas concepciones de la naturaleza y nuevos modos de ejercer su potestad sobre ella. Roy Porter manifestó hace unos años que en la 
renovación conceptual de la ciencia moderna Dios ocupó un lugar más remoto, y la naturaleza perdió su carácter sacrosanto, aún sin perder su autoridad (Porter y Teich, 1986). Y no le faltaba razón. El progreso cognoscitivo del hombre a través de su poder sobre la naturaleza abrió la puerta a nuevas visiones sobre el destino humano. Esta transformación en la manera de conocer no podría concebirse sin la aportación técnica generada por los artesanos y sin la consecuente teorización baconiana y cartesiana de la relación entre ciencia y naturaleza.

El dominio de la naturaleza mediante el cuerpo y los sentidos como forma de garantizar conocimiento sobre el mundo representa un legado que de manera alguna debe ser desdeñado. Se trata de una nueva epistemología corporal y sensorial basada en la experiencia y que contribuyó sobremanera al desarrolló de un nuevo método filosófico característico del mundo moderno. Durante los siglos XVI y XVII las diversas aproximaciones al conocimiento natural prepararon la soberanía y legitimación de una clase intelectual que, por lo general, nunca reconoció sus orígenes. Unos orígenes de los que se han apropiado disciplinas muy variadas alzando la bandera de la experiencia y el conocimiento de la naturaleza, a la manera de la más pura filosofía lockeana, desde finales del siglo XVII.

Para demostrar la continuidad entre una nueva epistemología artesanal fundada en las habilidades matemáticas y geométricas de aquellos cosmógrafos y cartógrafos como Ortelius, y la nueva filosofía natural basada en el esperanzador programa baconiano, convendría dirigir la mirada hacia los oficios de los practicantes, así como a sus complejas integraciones laborales que tradicionalmente han sido separadas por las subsecuentes prácticas disciplinares. Aquéllos que como Ortelius cercaron la naturaleza para dominar el mundo estaban motivados por características epistémicas similares a las de los astrónomos, cosmólogos y físicos. Los mapas, al igual que los astrolabios, los cuadrantes o los relojes solares ya anticiparon las premisas básicas de la restauración barroca. La imagen que apareció en la portada del Regimiento de navegación (1606) del cosmógrafo español Andrés García de Céspedes, donde una nave cruza las columnas de Hércules, parecía reivindicar y pronosticar la posibilidad de obtener conocimiento mediante saberes hasta entonces considerados auxiliares.

\section{NOTAS}

* La realización de este texto ha sido posible gracias, por un lado, a una beca de postgrado FPU concedida por el Ministerio de Educación y Ciencia y, por otro lado, al Proyecto de Investigación "Epistemología histórica; estilos de razonamiento científico y modelos culturales en el mundo moderno: el dolory la guerra" (HUM200763267) financiado por el Ministerio de Ciencia y Tecnología. Expreso aquí mi agradecimiento a Javier Moscoso y Javier Ordóñez, sin los cuales este texto no hubiese sido posible. Agradezco también a Alberto Fragio, Zoilo Egea y Juan Manuel Zaragoza sus siempre sugerentes comentarios sobre las primeras versiones de este artículo. De la misma forma, estoy en deuda con el profesor Robert J. Richards de la Universidad de Chicago.

1 Ya en la década de los noventa J. V. Field y Frank A. J. L. James editaron una recopilación de ensayos con el fin de acabar con el César. La atención ya no estaba puesta sobre los héroes y los episodios heroicos de la llamada Revolución Científica, sino en las figuras y eventos que por su escaso tratamiento se han convertido en marginales. A mi juicio este giro ha sido necesario, pero no suficiente. Por supuesto, no se agotan aquí las posibilidades del enorme trabajo de aquellos artesanos que tanto aportaron al entendimiento de problemas científicos particulares. Véase Field y James (1993).

2 Como un intento de responder a aquellos que aún se interrogan por
Aceptado: 1 de junio de 2009 
la legitimidad del conocimiento local de los talleres frente al conocimiento universal de la ciencia Smith ha rehecho una nueva narrativa externalista que reivindica la producción del conocimiento y la creatividad humanas. El arte naturalista, por ejemplo, no sólo representó un nuevo medio de comunicación visual, sino que además transformó las bases con las que hasta el momento se había entendido la ciencia. Ahora la ciencia también era ciencia visual, un nuevo camino para acceder a la verdad. Véase Smith (2004).

3 En los años veinte del siglo XX Leonardo Olschki defendió inicialmente la importante base empírica que habian aportado los artesanos, practicantes y viajeros al conjunto de la comunidad científica en la era moderna. Olschki valoró, como nunca antes se había hecho, a las artes y a las técnicas del Renacimiento siguiendo los pasos del empirismo extremo de Ernst Mach, la historia de la mecánica bajo la idea central de la economía de pensamiento, simplicidad o elección del mejor axioma. Véase Olschki (1919-27).

4 Reijer Hooykaas manifestó en los años cincuenta su simpatía hacia la consideración de los oficios y los artesanos. Su tesis mantiene que los navegantes y cosmógrafos portugueses de los siglos XV y XVI contribuyeron sin pretenderlo a la emergencia de la ciencia moderna, socavando, por un lado, la autoridad científica de físicos y matemáticos y fortaleciendo, por otro lado, la confianza en un método empírico cada vez más robusto. Hooykaas se superpone tanto a la concepción historiográfica de corte teleológica como a aquélla que intenta revivir el pasado. $Y$ lo hace tras la caracterización de los cuatro rasgos de la modernidad científica: la autoridad de la naturaleza y el triunfo del empirismo crítico sobre el racionalismo, la conquista de la naturaleza por parte de la ciencia experimental y del arte bajo las premisas de la observación y la experimentación artificial, una imagen mecanicista del mundo -pertrechada por ingenieros, alquimistas, cartógrafos, pilotos y constructores de instrumentos- frente al organicismo y, finalmente, la descripción del mundo natural mediante su matematización y cuantificación. A estos rasgos básicos Hooykaas añade la eclosión de un voluntarismo teleológico en contraposición al intelectualismo, la emancipación de trabajadores manuales $y_{\text {, como fruto de }}$ la revolución geográfica, el desarrollo de la historia natural y del cambio epistémico-metodológico basado en la experiencia y ya no tanto en el estudio bibliográfico. Véase Hooykaas (1987).

5 El célebre historiador de la cartografia David Woodward ha apoyado recientemente en el capítulo inicial del tercer volumen de The History of Cartography Proyect iniciado en 1987 de la mano de J. B. Harley las originales ideas de Zilsel sobre los "artesanos superiores". Véase Woodward (2007).

6 Richard S. Westfall repasó, en un artículo muy original y siguiendo la línea de Crombie, aquellas autoridades científicas que habian desarrollado su trabajo entre la época en que nació Copérnico y 1680 a través del Dictionary of Scientific Biography [Charles C. Gillispie (ed.), 16 vols., New York, Charles Scribner and Sons, 1970-80]. Para sorpresa de muchos el resultado fueron 630 personas de las cuales 90 o el 14,3\% eran cartógrafos, un buen porcentaje dentro de lo que él ha Ilamado, el catálogo de la comu- nidad científica de ese período. Un catálogo completado por disciplinas tan significativas como la ingeniería militar, la ingeniería hidráulica, la navegación o incluso la ciencia industrial. Cada uno de los nombres mayores de la cartografía era, sin duda, una autoridad dentro de la historia de la ciencia. Frisius y Cassini son algunos de ellos. Westfall intenta promover una nueva concepción de lo que se ha conocido por Revolución Científica, destacando el papel de los matemáticos como promotores de los grandes problemas técnicos de la cosmografía, la cartografía y la navegación. Fueron los matemáticos, según Westfall, quienes enseñaron a los navegantes cómo determinar la latitud en cualquier punto del globo, cómo determinar la longitud (no resuelto hasta el siglo XVIII) y cómo enmendar las distorsiones de la carta plana. Con este propósito creó Felipe II la Academia de Matemáticas de Madrid en 1582. De hecho, aquéllos que se hicieron con una reputación en matemáticas desarrollaron de forma paralela trabajos topográficos y cartográficos. Uno de cada siete científicos de su catálogo llevó a cabo alguna labor cartográfica y uno de cada cinco contribuyó al desarrollo de la instrumentación. Véase Westfall (1993).

7 Con anterioridad al Theatrum construyó varios mapas. En 1564 levantó un mapa del mundo llamado Nova Totius Orbis luxta Neo. En 1565 realizó un mapa de Egipto. Al año siguiente apareció un mapa de Tierra Santa (1566). En 1567 vio la luz su mapa de Asia titulado Asiae Orbis Partium Maximae Nova Descriptio. En 1568 fabricó su Arx Británica. Se piensa que antes de 1570 también publicó un mapa del Paraíso. A 1570 perte- 
nece el mapa de España, Hispaniae Nova Descriptio. Posteriormente, en 1571 construyó su Romani Imperii Imago. Véase Van den Broecke, Van der Krogt y Meurer (1998).

\section{BIBLIOGRAFÍA}

Bacon, Francis (2002): Instauratio Magna, México, Porrua.

Bacon, Francis (2004): Novum Organum, Buenos Aires, Losada.

Barrera-Osorio, Antonio (2006): Experiencing Nature: The Spanish American Empire and the Early Scientific Revolution, Austin, University of Texas Press.

Bennett, Jim (1986): "The Mechanics' Philosophy and the Mechanical Philosophy", History of Science, 24, 1-28.

Bennett, Jim (1991): "Geometry and Surveying in Early-Seventeenth-Century England", Annals of Science, 48(4), 345-354.

Bennett, Jim (1998): "Projection and the Ubiquitous Virtue of Geometry in the Renaissance", Crosbie Smith y Jon Agar (eds.), Making Space for Science: Territorial Themes in the Shaping of Knowledge, London, Macmillan, 27-38.

Bennett, Jim (2002): "Geometry in Context in the Sixteenth Century: The View from the Museum", Early Science and Medicine, 7(3), 214-230.

Bennett, Jim (2003): "Cosimo's Cosmography: The Palazzo Vecchio and the History of Museums", M. Beretta, P. GaIluzi y C. Triarico (eds.), Musa Musaei: Studies on Scientific Instruments and Collections in Honour of Mara Miniati, Florence, Leo S. Olschki, 191-197.

Besse, Jean-Marc (2007): "El nacimiento del atlas moderno: Ortelius, Lafreri", Francisco Jarauta (ed.), El mundo de los mapas, Santander, Fundación Marcelino Botín, 93-129.
Broecke, Marcel van den, Krogt, Peter van der y Meurer, Peter (1998): Abraham Ortelius and the First Atlas: Essays Commemorating the Quadricentennial of his Death, 1598-1998, t'GoyHouten, HES Publishers.

Brotton, Jerry (2003): El bazar del Renacimiento, Barcelona, Paidós.

Burke, Peter (1996): La cultura popular en la Europa moderna, Madrid, Alianza.

Capel, Horacio (1985): "Geografía y arte apodemica en el siglo de los viajes", Geo Crítica, 56, 3-59.

Cerezo Martínez, Ricardo (1994): La cartografía náutica española en los siglos XIV, XV y XVI, Madrid, CSIC.

Cook, Harold J. (2007): Matters of Exchange: Commerce, Medicine, and Science in the Dutch Golden Age, New Haven and London, Yale University Press.

Crombie, Alistair C. (1980): "Science and the Arts in the Renaissance: the Search for Truth and Certainty, Old and New", History of Science, 18, 233-246.

Cunningham, Andrew y Williams, Perry (1993): "De-centring the 'big picture': The Origins of Modern Science and the modern origins of science", British Journal for the History of Science, 26, 407-32.

Daston, Lorraine y Park, Katharine (ed.) (2006): The Cambridge History of Science: Early Modern Science (vol. 3), Cambridge, Cambridge University Press.

Dear, Peter (2001): Revolutionizing the Sciences: European Knowledge and its Ambitions, 1500-1700, London, Palgrave.

Fernández-Armesto, Felipe (2007): "Maps and Exploration in the Sixteenth and Early Seventeenth Centuries", David Woodward (ed.), The History of Cartography: Cartography in the European Renaissance, vol. 3, Chicago \& London, The University of Chicago Press, 738-770.
Field, J. V. y James, F. (eds.) (1993): Renaissance and Revolution: Humanists, Scholars, Craftsmen and Natural Philosophers in Early Modern Europe, Cambridge, Cambridge University Press.

Findlen, Paula (1993): "Controlling the Experiment: Rhetoric, Court Patronage and the Experimental Method of Francesco Redi", History of Science, 31(91), 35-64.

Findlen, Paula (1996): Possesing Nature: Museums, Collecting, and Scientific Culture in Early Modern Italy, London, University of California Press.

Floris Cohen, H. (1994): The Scientific Revolution: A Historiographical Inquiry, Chicago \& London, The University of Chicago Press.

Gerbi, Antonello (1978): La naturaleza de las Indias Nuevas, México, Fondo de Cultura Económica.

Hall, Rupert (1962): "The Scholar and the Craftsman in the Scientific Revolution", Marshall Clagett (ed.), Critical Problems in the History of Science, Madison, The University of Wisconsin, 3-23.

Hooykaas, Reijer (1987): "The Rise of Modern Science: When and Why?", British Journal fir History of Science, 20, 453-473.

Keller, A. C. (1950): "Zilsel, the Artisans, and the Idea of Progress in the Renaissance", Journal of the History of Ideas, 11, 235-40.

Kuhn, Thomas S. (1993): La tensión esencial, Madrid, Fondo de Cultura Económica.

Lux, David S. (1991): "The Reorganization of Science 1450-1700", Bruce T. Moran (ed.), Patronage and Institutions: Science, Technology, and Medicine at the European Court 1500-1750, Suffolk, The Boydell Press, 185-194.

Martín-Merás, Maria Luisa (1993): Cartografía maritima hispana: la imagen de América, Madrid, Lunwerg. 
Moran, Bruce T. (ed.) (1991): Patronage and Institutions: Science, Technology, and Medicine at the European Court 1500 1750, Suffolk, The Boydell Press.

Olschki, Leonardo (1919-27): Geschichte der neusprachlichen wissenschaftlichen Literatur, 3 vols., Heidelberg, Leipzig, Florencia y Halle.

Pimentel, Juan (2001): "The Iberian Vision: Science and Empire in the Framework of a Universal Monarchy, 1500-1800", Osiris, 15, 17-30.

Porter, Roy y Teich, Mikulas (eds.) (1986): Revolution in History, Cambridge, Cambridge University Press.

Portuondo, Maria (2005): Secret Science: Spanish Cosmography and the New World, Ph. D. diss., Baltimore, The Johns Hopkins University.

Ortelius, Abraham (1570): Theatrum Orbis Terrarum, Amberes.

Ortelius, Abraham (1588): Teatro de la Tierra Universal, Amberes.

Randall, John Herman (1961): The School of Padua and the Emergence of Modern Science, Padua.

Rodríguez de la Flor, Fernando (1999): La península metafísica: arte, literatura y pensamiento en la España de la Contrarreforma, Madrid, Biblioteca Nueva.
Rodríguez de la Flor, Fernando (2005): Pasiones frías: secreto y disimulación en el Barroco hispano, Madrid, Marcial Pons.

Sandman, Alison D. (2001): Cosmographers vs. Pilots: Navigation, Cosmography, and the State in Early Modern Spain, Ph. D. diss., Madison, University of Wisconsin.

Smith, Pamela H. (1994a): "Alchemy as a Language of Mediation at the Habsburg Court", Isis, 85(1), 1-25.

Smith, Pamela H. (1994b): The Business of Alchemy: Science, and Culture in the Holy Roman Empire, Princeton, Princeton University Press.

Smith, Pamela H. (1999): "Science and Taste: Painting, Passions, and the New Philosophy in Seventeenth-Century Leiden", Isis, 90(3), 421-461.

Smith, Pamela H. (2000): "Vital Spirits: Redemption, Artisanship, and the New Philosophy in Early Modern Europe", Margaret J. Osler (ed.), Rethinking the Scientific Revolution, Cambridge, Cambridge University Press, 119-135.

Smith, Pamela H. y Findlen, Paula (eds.) (2002): Merchants and Marvels, New York and London, Routledge.

Smith, Pamela H. (2004): The Body of the Artisan: Art and Experience in the
Scientific Revolution, Chicago and London, University of Chicago Press.

Westfall, Richard S. (1993): "Science and technology during the Scientific Revolution: an empirical approach", J. V. Field, Frank A. J. y L. James (eds.), Renaissance and Revolution: Humanists, scholars, craftsmen and natural philosophers in early modern Europe, Cambridge, Cambridge University Press, 63-72.

Woodward, David (2007): "Cartography and the Renaissance: Continuity and Change", David Woodward (ed.), The History of Cartography: Cartography in the European Renaissance, vol. 3, Chicago \& London, The Universiy of Chicago Press, 3-24.

Zilsel, Edgar (1940): "Copernicus and Mechanics", Journal of the History of Ideas, 1, 113-118.

Zilsel, Edgar (1941): "The Origins of William Gilbert's Scientific Method", Journal of the History of Ideas, 2, 1-32.

Zilsel, Edgar (1942): "The Sociological Roots of Science", American Journal of Sociology, 47(4), 544-562.

Zilsel, Edgar (1945): "The Genesis of the Concept of Scientific Progress", Journal of the History of Ideas, 6, 325349. 